Accepted version of

Coelho, G. L. H., Monteiro, R. P., Vilar, R., Hanel, P. H. P., Moizéiz, H. B. C., \& Gouveia, V. V. (2019). Psychometric evidence of the Short Almost Perfect Scale (SAPS) in Brazil. The Counseling Psychologist.

\title{
Psychometric evidence of the Short Almost Perfect Scale (SAPS) in Brazil
}

Gabriel Lins de Holanda Coelho, University College Cork, Ireland Renan Pereira Monteiro, Federal University of Mato Grosso, Brazil

Roosevelt Vilar, Massey University, New Zealand

Paul H. P. Hanel, University of Bath, United Kingdom Heloísa Bárbara Cunha Moizéis, Federal University of Paraíba, Brazil Valdiney Veloso Gouveia, Federal University of Paraíba, Brazil

Contact E-mail: linshc@gmail.com (Gabriel Coelho), renanpmonteiro@gmail.com (Renan Pereira)

Acknowledgements: The authors thank Kenneth Rice for providing data from his original validation paper (Rice et al., 2014), which allowed us to test for measurement invariance across countries. 
Abstract: Perfectionism can be understood as a personality trait that establishes excessively high standards for the performance of individuals and ostensibly critical self-evaluations. It is associated with a range of variables, such as anxiety, suicidal tendencies, depression, and low satisfaction with life. Rice et al. (2014) proposed the Short Almost Perfect Scale (SAPS), which overcame some limitations of previous measures (e.g., ambiguity, non-necessary factors). In the present research, we provide psychometric evidence of the SAPS in Brazil. The original two-factor structure was replicated. The items showed good discrimination, level of difficulty, and informativeness for the overall measure. The SAPS also presented acceptable reliability levels, and full measurement invariance across participants' gender, and partial invariance across countries (Brazil and USA). Finally, perfectionism was meaningfully associated with personality traits and human values. In sum, our findings suggest that the SAPS is psychometrically adequate for further use in Brazil.

Keywords: Perfectionism; validation; psychometric properties.

\section{Scholarship statement:}

Perfectionism can have a negative impact on people's life. For example, perfectionism is associated with anxiety and suicidal tendencies. A fundamental requirement to study perfectionism is its reliable and valid measurement. The present research provides psychometric evidence for the Short Almost Perfect Scale (SAPS) in Brazil through a range of methods. Our research shows that the SAPS is a reliable and psychometrically robust measure, which can benefit researchers and practitioners alike. Further, our research also contributes towards the cross-cultural understanding of perfectionism. 


\section{Introduction}

Perfectionism can be understood as a personality trait that establishes excessively high standards for individuals' performance and critical self-evaluations (Frost, Marten, Lahart, \& Rosenblate, 1990; Hewitt \& Flett, 2014). Perfectionism can be relevant in many situations. For example, if you are starting a new business, it is important to invest time and effort to make your company known and to establish a good reputation. Setting high standards for yourself - that is, being (somewhat) perfectionistic - might help to be perceived as reliable and attract customers. At university, students who do everything they can to achieve very good grades can be seen as perfectionists. However, perfectionism can also be(come) problematic. Extreme perfectionists are compulsive in reaching perfection, being rigid and inflexible in their thoughts, actions, and feelings. This might drive them to pursue perfection in situations in which being perfect is irrelevant which becomes an indicator of personality dysfunction; Flett \& Sherry, 2016). Also, extreme perfectionists tend to demand perfection from others.

Research has shown significant correlations of perfectionism with several variables relevant to counseling, such as fatigue, emotional exhaustion, anxiety, and suicidal tendencies (e.g., Flaxman, Ménard, Bond, \& Kinman, 2012; Smith et al., 2017), which makes its reliable and valid measurement pivotal. In counseling psychology, reliable and valid measurement of perfectionism will help to provide a better understanding on the underlying mechanisms that link perfectionism to such variables. Specifically, perfectionism has a maladaptive side, that may relate to an increase in psychopathologies (Curran \& Hill, 2019), making people more vulnerable to depression, anxiety (Moroz \& Dunkley, 2019), and increase the risk of suicide (Hamilton \& Schweitzer, 2000). 
Despite the relevance of perfectionism for mental health, there is little research on it in Brazil. Previously, the Sport-Multidimensional Perfectionism Scale-2 (SMPS-2) was validated in Brazil, allowing sport psychologists to better understand the phenomena amongst athletes (Nascimento Junior, Vissoci, Lavallee, \& Vieira, 2015). In another study, perfectionism was associated with eating disorders in young women (Fortes et al., 2015). Also, perfectionism showed significant associations with psychiatric disorders. It showed higher scores in individuals with obsessive-compulsive disorder and eating disorders than in non-clinical participants (Maia et al., 2009). Finally, the interaction between perfectionism and sensory phenomena distinguished OCD participants from control subjects (Lee et al., 2009). Despite of these promising findings, more research is needed in Brazil to get a better understanding of perfectionism, its correlates, antecedents, and consequences. We speculate that this lack of research can also partly be attributed to the lack of a reliable and valid measure of perfectionism in Brazil. Thus, in the present paper we close this gap in the literature by validating a perfectionism scale. This scale might also be useful for Brazilian counseling psychologists, because it allows them, for example, to test the efficacy of interventions that can aim reduce the maladaptive aspects of perfectionism and enhancing the quality of life and well-being.

The present research aims to test whether the Short Almost Perfect Scale (SAPS; Rice, Richardson, \& Tueller, 2014) is psychometrically suited in the Brazilian context. That is, we assess whether the structure of the SAPS replicates in a non-Western country (Henrich, Heine, \& Norenzayan, 2010), which is somewhat neglected in psychological research. Furthermore, the SAPS might help to reveal specific crosscultural differences between Brazil and other countries. For instance, Curran and Hill (2019) suggested that many cultural aspects can influence the development of 
perfectionism, such as the emergence of neoliberalism and the idea of meritocracy. However, these authors considered in their analysis rich, industrialized, and developed countries. In contrast, our research focus on a very inequal (in terms of wealth distribution) and developing country. Brazil occupies the 150th position in the world ranking of economic liberty (Index of Economic Freedom, 2019), the 105th in the world ranking of perception of corruption (Transparency International, 2018), and is the 10th most inequal country in the world (Index Mundi, n.d.).

In a corrupt and inequal environment being perfect may not be enough to reach one's goals. To achieve these goals, it might be more effective to use deceptive and transgressive behaviors, such as taking advantage of others (Miura, Pilati, Milfont, Ferreira, \& Fischer, 2019). Indeed, these behaviors have been labelled Jeitinho. Jeitinho includes the use of corruption and norm breaking as problem-solving strategies (Ferreira, Fischer, Porto, Pilati, \& Milfont, 2012). Another cultural aspect that makes it relevant to study perfectionism in Brazil is the performance of Brazilian students in the Programme for International Student Assessment (Organização para a Cooperação e Desenvolvimento Económico, 2015). Brazilian students score below average. Further, there are almost 13 million unemployed people in Brazil (Agência IBGE, 2019). Together, this suggests that being perfectionistic does not pay off to the same extent as in more egalitarian and successful countries. Instead, people might be more frequently incentivized to take 'shortcuts' and cheat (cf. Ferreira et al., 2012) than to work hard.

\section{Types and Factors}

Hamacheck (1978) distinguished two types of perfectionism, normal and neurotic. Normal perfectionism can be understood as positive: Individuals tend to pursue realistic objectives in a very efficient and effective way, allowing themselves to fail, without compromising their well-being. In contrast, neurotic perfectionism is about 
setting unrealistic high standards, being driven by their fear of failure, and thinking that the own efforts are never enough to achieve personal goals. Stoeber and Otto (2006) argued that extensive research supports Hamacheck's types of perfectionism (e.g., Frost, Heimberg, Holt, Mattia, \& Neubauer, 1993; Hill et al., 2004).

Following Hamacheck (1978), research has consistently found two factors of perfectionism (e.g., Rice et al., 2014; Slaney, Rice, Mobley, Trippi, \& Ashby, 2001): standards and discrepancy. The standards factor represents high personal performance expectations, which arise in people who desire to achieve perfection and avoid failures; in other words, rigorous behaviors for themselves (Rice et al., 2014). On the other hand, the discrepancy factor represents the "perceived gap between personal standards and one's evaluation of having met those standards" (Rice et al., 2014, p. 368). That is, the perceived failure in achieving desired levels of perfectionism. This discrepancy is associated with several pathologies such as depression, anxiety, and low satisfaction with life (e.g., Elion, Wang, Slaney, \& French, 2012; Sherry, Mackinnon, Macneil, \& Fitzpatrick, 2012). In addition, these studies have also proposed a third factor of perfectionism: order, which is related to the need to reach high standards - although it reflects more the preference for being organized. However, although order was initially a factor of the Almost Perfect Scale - Revised (APS-R), it was eventually dismissed. It showed acceptable psychometric indices (Stoeber \& Otto, 2006), but no predictive validity. Also, order seemed more like a consequence of being perfectionistic, than a regular aspect of the construct itself. Thus, the authors disregarded this factor in the Short Almost Perfect Scale (SAPS), and only kept standards and discrepancies (Rice et al., 2014). 


\section{APS-R and SAPS}

We first describe the widely used APS-R, before we discuss the SAPS. The APS-R originally consisted of 23 items covering three factors: Standards, discrepancy, and order. The APS-R can assess different profiles of perfectionists, which allows to categorize people depending on their responses (Ashby, Rice, \& Kutchins, 2008; Rice \& Ashby, 2007). Individuals who score high in standards and low in discrepancy are classified as adaptivelhealthy perfectionists (which can be seen as the normal type in Hamacheck's classification). Individuals who score high on both factors are classified as maladaptivelunhealthy perfectionists, a type commonly associated with poor mental health (Rice et al., 2014). Individuals who score low on standards but high on discrepancy are classified as self-critical perfectionists (Arana \& Furlan, 2016; Gaudreau, 2012). Finally, individuals who score low on both factors are labelled nonperfectionists.

The APS-R was developed and validated in the United States (Slaney et al., 2001), and found to be psychometrically suitable in several countries, including Argentina (Arana, Rice, \& Ashby, 2017), Japan (Nakano, 2009), China (Wang, Slaney, \& Rice, 2007), and South Korea (Park, 2009). Although being psychometrically suited, its applicability was not consistent across all the countries. For instance, Wang et al. (2007) identified a new profile of perfectionists (high standards $\backslash$ higher-discrepancy scores), emerged apparently because of cultural differences. Also, the seemingly orthogonal factors did not hold in Argentina (Arana et al., 2017), not achieving measurement invariance for standard items, which raised concerns about the crossnational comparability of the measure. Nevertheless, the APS-R correlated to several constructs, such as perceived stress, drinking to cope (Rice \& Arsdale, 2010), adult 
attachment, hopelessness, life satisfaction (Gnilka, Ashby, \& Noble, 2013), and wellbeing (Wang et al., 2007).

Therefore, the APS-R contains some limitations, such as its length, an unnecessary third factor (order), ambiguity, and redundancy of some items (Rice et al., 2014). To address these limitations, a brief version of the APS-R was developed, the Short Almost Perfect Scale (SAPS), which consists of 8 items equally spread across two-factors: standards and discrepancy (Rice et al., 2014). The measure evaluates perfectionism through the patterns of efforts and concerns of individuals (Rice et al., 2014). Overall, the measure is psychometrically suitable with its two-factor structure (e.g., CFI = .96; RMSEA = .05), and is reliable (standards, $\alpha=.85$, and discrepancy, $\alpha=$ .87). The authors found that the APS-R is invariant across gender, which allows to compare women and men in a meaningful way (e.g., Davidov, Meuleman, Cieciuch, Schmidt, \& Billiet, 2014). Finally, Rice et al. found meaningful correlations between the Big-5 personality traits and perfectionism: standards was significantly and positively correlated with conscientiousness, while discrepancy was significantly correlated to neuroticism (negatively) and conscientiousness (positively).

\section{The Present Research}

Since findings of psychological studies can differ within and across countries (e.g., Hanel \& Vione, 2016; Henrich et al., 2010), replications are necessary to test whether the SAPS can be used in non-Western countries. In the present research, we test the reliability and validity of the SAPS (Rice et al., 2014) in Brazil. This not only allows us to test whether the factorial structure of SAPS replicates in a non-Western country, but also allows us to extend previous research by correlating the SAPS dimensions with personality traits and human values. We expected that the two-factor structure would also replicate in Brazil. 
To provide a powerful test of the psychometric properties of the SAPS, we use a range of analyses, which were only partly used by Rice et al. (2014) when they introduced the SAPS. Specifically, besides the usual techniques used in previous studies (e.g., exploratory factor analysis, confirmatory factor analysis), we assessed the SAPS through Item Response Theory, which is an important technique to explain the associations between the item and the underlying construct (Cappelleri, Jason Lundy, \& Hays, 2014). Also, to provide more information regarding the transcultural aspects of the measure, participants from our sample (Brazil) were compared to US-based participants whose responses were reported in one of the original validation studies (Rice et al., 2014), through measurement invariance, using Multigroup Confirmatory Factor Analysis.

Finally, based on previous studies (e.g., Ulu \& Tezer, 2010), and characteristics that define standards (e.g., being competent, imaginative, and assertive) and discrepancy (e.g., anxiety, depression), we expected to find positive correlations between conscientiousness, openness to change, and extroversion with standards, while neuroticism was expected to correlate positively with discrepancy. No research explored the relations between human values and perfectionism, to the best of our knowledge. Human values are guiding principles in people's life and serve different motives and needs (Gouveia et al., 2014; Schwartz, 1992). For example, some of the values such as those related to promotion, power, or achievement, refer to self-enhancing motives. We expected that such self-enhancing values are related to standards, because perfectionism can also serve self-enhancing motives and needs. This reasoning is in line with previous research that has found that perfectionism is related to narcissism (Sherry, Gralnick, Hewitt, Sherry, \& Flett, 2014), which in turn is related to power, prestige, and 
achievement (Kajonius, Persson, \& Jonason, 2015). Further, self-enhancing values were positively associated with depression (Elion et al., 2012; Hanel \& Wolfradt, 2016).

\section{Method}

\section{Participants and Procedure}

Participants were 421 Brazilians (women $=245$, men $=176$ ), with an age range from 14 to 67 years $\left(M_{\text {age }}=23.98, S D=6.49\right)$. The majority of the participants aimed to obtain a University degree during the time of the data collection or had recently obtained one $(n=404)$. Also, most of the participants declared themselves as heterosexuals $(n=332 ; 78.9 \%)$, and Catholics $(n=161 ; 38.2 \%)$ or religiously unaffiliated $(n=155 ; 36.8 \%)$. The study was advertised on social networks (e.g., Facebook, Instagram) with a short description of the purpose of the study and a link to an online survey.

Also, the data of a student sample described by Rice et al. (2014) in one of their studies was kindly shared with us $\left(n=340 ; M_{\text {age }}=19.40, S D=1.46\right.$; women $=264$, men $=67$, missing data $=9$ ), which allowed us to test for measurement invariance. Five participants were removed from this sample, because they were outliers as defined by Rice et al.. These participants were recruited from undergraduate courses and received research credits for their participation.

\section{Measures}

Short Almost Perfect Scale (Rice et al., 2014). The SAPS assess perfectionism through individuals' strivings and concerns. It consists of eight items, equally divided in two factors, Standards (e.g., 1. I have high expectations for myself) and Discrepancy (e.g., 6. My performance rarely measures up to my standards). Responses were given on a seven-point scale (1 - Strongly Disagree to 7 - Strongly Agree). For its translation (See full Brazilian-Portuguese version in appendix), it was requested the help of three 
bilingual collaborators, in which two made the translation into Brazilian-Portuguese and another conducted a back-translation. Subsequently, a pilot study was carried out with the participation of twenty undergraduate students, equally distributed in terms of gender, in which the comprehension of the items and instructions was verified. No change was necessary.

Ten-Item Personality Inventory (TIPI; Gosling et al., 2003). This scale measures the Big-5 factors of personality, with two items per factor that are averaged: openness to experiences (Inter-item correlation, $r=.28)$, conscientiousness $(r=.30)$, extraversion $(r$ $=.51)$, agreeableness $(r=.12)$, emotional stability $(r=.48)$. Participants reported to what extent ten adjectives are characteristics for their personality, including "Extraverted, enthusiastic" (extraversion), and "Critical, quarrelsome" (neuroticism). Responses were given on a seven-point scale (1 - Disagree Strongly; 7 - Agree Strongly). It is important to note that Gosling et al.'s (2003) aim was to create a personality measure that optimized validity (e.g., content validity), instead of an instrument with high reliability levels. This explains the partly low inter-item correlations of this study but also of other studies. Despite the low inter-item correlations, the TIPI is a widely used measure (see https://gosling.psy.utexas.edu/scales-weve-developed/ten-item-personality-measuretipi/).

In addition, a subset of 338 participants completed also the Basic Values Survey (BVS; Gouveia, Milfont, Fischer, \& Santos, 2008). The BVS is composed of 18 items which are equally distributed among six subfunction of values: excitement (Cronbach's alpha, $\alpha=.61$, mean of inter-item correlations, $\mathrm{Mr} .=.36)$, promotion $(\alpha=.62, \mathrm{Mr} .=$ $.35)$, suprapersonal $(\alpha=.51, \mathrm{Mr} .=.28)$, existence $(\alpha=.50, \mathrm{Mr} .=.25)$, interactive $(\alpha=$ $.61, \mathrm{Mr} .=.34)$, and normative $(\alpha=.70, \mathrm{Mr} .=.47)$ values. Participants were instructed to 
rate how important they consider each of the values as a guiding principle in their life. Example items include "Pleasure (To live for the moment; to satisfy all your desires)" and "Emotion (To enjoy challenges or unknown situations; to look for adventure)". Responses were given on a seven-point scale (1 - Completely Unimportant; 7 - Of the Utmost Importance). Considering that alpha is sensitive to the number of items, and low alphas are common to value measures (e.g., Gouveia, Milfont, \&, Guerra, 2014; Schwartz, 2005), we decided to calculate the mean of inter-item correlations, providing additional evidence that indicate acceptable coefficients for research purposes.

\section{Data Analysis}

The "R" software was used (R Development Core Team, 2015) to perform all the analyses, using several packages. First, to assess the structure, the sample was divided for an exploratory factor analysis $(\mathrm{EFA} ; \mathrm{N}=211)$ and a confirmatory factor analysis (CFA; $N=210)$. The EFA was used to identify the structure of SAPS in Brazil, using the Principal Axis Factoring (PAF) procedure with promax rotation. An EFA is necessary to assess the underlying theoretical structure of a set of items in a new context. That is, it allows us to check how the items are interrelated. Therefore, as the SAPS was previously not been used in Brazil, the EFA is an important first step. The Psych and $n$ Factors statistical packages were used (Raiche, Walls, Magis, Riopel, \& Blais, 2013; Revelle, 2013). Following Steven's (2012) recommendation for sample sizes of 200, we considered items with loadings higher than $|.364|$ as relevant for a factor.

Next, we assessed the structure through CFA, using the Maximum Likelihood Robust (MLR) method. To evaluate whether the fit indices are sufficient, we relied on the following cut-off values (Hair, Black, Babin, \& Anderson, 2015; Tabachnick \& Fidell, 2013): (1) Chi-square ( $\chi 2)$, which is recommended to be non-significant; (2) 
Comparative fit index (CFI) and (3) Tucker-Lewis Index (TLI), which require to be higher than .90; and (4) Root mean square error approximation (RMSEA), which must be lower than 80 .

For all further analysis, we used the full Brazilian sample. We then assessed the discrimination, difficulty, and informativeness of the items with the Multidimensional Item Response Theory (MIRT) package (Chalmers, 2012) in R software. Within the MIRT analysis, we used the Graded Response Model, due to the polytomous nature (more than two answer categories) of the measure (Samejima, 1968).

To test whether the SAPS can be meaningfully compared across gender and countries, we performed a multigroup confirmatory factor analysis (MGCFA; MLR Estimator). A MGCFA tests whether the groups understand the measure in an equivalent way, allowing meaningful comparisons across the groups considered. In this case, a complete measurement invariance would indicate that the SAPS can be used for gender and cross-cultural comparisons. Specifically, we tested whether configural, metric, and scalar invariance can be established (Milfont \& Fischer, 2010), which should present values of $\Delta \mathrm{CFI} \leq .01$, and $\Delta \mathrm{RMSEA} \leq .015$ (Chen, 2007; Cheung \& Rensvold, 2002).

Finally, McDonald's omega and Cronbach's alpha were considered to assess the reliability of the measure. The reliability of the measures was investigated through the userfriendlyscience package (Peters, 2016). The convergent validity was assessed through correlations with personality traits and human values.

\section{Results}

\section{Exploratory Factor Analysis}

For the EFA and CFA, the sample was divided. An Exploratory Factor Analysis was performed with 211 participants. First, KMO and Bartlett's test measured the 
sampling adequacy (Hair et al., 2015), with results supporting the performance of an $\mathrm{EFA}\left[\mathrm{KMO}=.77\right.$ and the Bartlett sphericity test, $\left.\chi^{2}(28)=497.3, p<.001\right]$. All criteria used to determine the number of factors to extract (Kaiser, Cattel, Horn, Optimal Coordinates and Acceleration Factor) pointed to a two-factor structure of SAPS in Brazil. Next, a PAF showed good factorial loadings for all items (Table 1).

\section{[TABLE 1 AROUND HERE]}

\section{Confirmatory Factor Analysis}

With the other half of the sample, we performed a CFA to confirm the twofactor structure. The following indicators were obtained using the MLR estimator: $\chi^{2}$ $(19)=64.823, p<.001, \mathrm{CFI}=.89, \mathrm{TLI}=.84$ and RMSEA $=.11(\mathrm{CI} 90 \%=.082-.134)$.

The fit improved when we allowed the errors from items 6 and 8 to be correlated because of a high modification index $(\mathrm{MI}=29.29): \chi^{2}(18)=44.12, p<.001, \mathrm{CFI}=.94$, $\mathrm{TLI}=.90$ and RMSEA $=.08(\mathrm{CI} 90 \%=.055-.112)$. All the factorial weights (lambdas) were statistically different from zero $(\lambda \neq 0 ; \mathrm{z}>1.96, p<.05)$, varying between .51 (Item 1) and .81 (Item 7). The final structure can be seen in Figure 1.

\section{[FIGURE 1 AROUND HERE]}

\section{Item Response Theory}

For all further analysis, we used the full Brazilian sample. Item response theory was used to assess the item discriminations and difficulties were assessed. The parameter labelled $a$ (Colum 1) in Table 2 shows item discrimination, which represents the ability of the item to discriminate between individuals varying in the latent trait. According to Baker (2001), higher values indicate items with higher discrimination. Six items were very highly discriminative (a > 1.7), whereas one (Item01) was highly (a between 1.35 and 1.69), and a last item (Item02) moderately discriminative (a between 0.65 and 1.34). 


\section{[TABLE 2 AROUND HERE]}

Item difficulties are displayed as b1-b6 in Table 1. They estimate which level of the latent trait the individual needs to endorse to select the next higher response option. Items are recommended to neither be too easy nor too difficult (e.g., recommended the means across b's to be between 0 and $+/-1.5$; Rauthmann, 2013). Results showed that five of the items were between the recommended values, while the three others were close.

Next, item information curves (IIC; Figure 2) and test information curves (TIC; Figure 3) were assessed. The IIC test how much information an item shares with the total information of the measure (Castro, Trentini, \& Riboldi, 2010), with a higher I $(\theta)$ indicating higher informativeness. The TIC are based on the amount of information all items add to the total amount of information, and it is directly related to the reliability of the scale, with a total information of 10 being equivalent to a reliability of .90

(Cappelleri et al., 2014). Most the items were reasonably informative, with item 8 being the most informative one (Figure 2) and item 2 the least informative. For the test information curves, results suggest a reasonable spread of discrimination across the latent range of perfectionism.

\section{[FIGURES 2 AND 3 AROUND HERE]}

\section{Measurement Invariance}

We tested whether the SAPS is invariant across gender and countries, considering three models (configural, metric, scalar; Milfont \& Fischer, 2010). Achieving measurement invariance indicates that women and men are answering the scale in an equivalent way. This allows meaningful comparisons between the groups (e.g., means comparisons, correlations), once they are answering to the measure in the same way. As can be seen in Table 3, results showed full invariance for gender. 
However, between the countries, scalar invariance was not achieved. Therefore, we unconstrained the intercepts of items 1 and 5, reducing the $\Delta$ CFI to .008 - below the recommended threshold of .01 .

\section{[TABLE 3 AROUND HERE]}

\section{Reliability}

To test whether the two scales are sufficiently reliable, we computed McDonald's Omega and Cronbach's alpha. For both factors, discrepancy $(\omega=.80$ and $\alpha$ $=.79)$ and standards $(\omega=.76$ and $\alpha=.75)$, the results were above the recommended thresholds of .70 (Kline, 2013), indicating satisfactory to good reliability. For the complete scale, omega was .78 and alpha .77.

\section{Convergent Validity}

As perfectionism is a personality trait, we decided to test its associations to the Big-5 personality traits. Discrepancy was significantly and negatively correlated with conscientiousness, extraversion, openness to experience, and emotional stability, while standards was positively correlated with conscientiousness and openness to experiences. For the human values, discrepancy was positively correlated with suprapersonal values, while standards was correlated with suprapersonal, interactive, promotion, and existence. The full results can be seen in Table 4 .

\section{[TABLE 4 AROUND HERE]}

\section{Discussion}

This research aimed to provide psychometric evidence for the SAPS (Rice et al., 2014) in Brazil. Our research relied on analytical approaches (e.g., Item Response Theory, cross-cultural measurement invariance) that enhance the psychometric findings of the measure and which have not been used in the original paper introducing the 
SAPS (Rice et al., 2014). Also, in addition to convergent validity with personality traits, we investigated for the first-time correlations between human values and perfectionism.

\section{SAPS Structure, Reliability, and Item Parameters}

First, we split the full sample to perform two types of analyses to assess the structure of the SAPS in Brazil. Through an exploratory factor analysis, the two-factor structure proposed by Rice et al. (2014) was supported using multiple criteria, with all items presenting high loadings $(>|.40|)$ on their respective factor. To further confirm this structure through a more robust method, a confirmatory factor analysis was performed. Once again, results indicated a good model fit for the two-factor structure. Using the full sample, the reliability levels, operationalized through McDonald's omega and Cronbach's alpha (Kline, 2013), attested the psychometrical quality of the measure for the Brazilian context. Besides the original research by Rice et al. (2014), our findings are in line with other validations of the SAPS, that also replicated the twofactor structure (e.g., Loscalzo, Rice, Giannini, \& Rice, 2018; Wang, Permyakova, \& Shevelena, 2016).

Results showed that all items from SAPS ranged from moderately to very highly discriminative (Baker, 2001), being recommended to differentiate individuals with different levels of perfectionism. Also, five of the eight items showed difficulty levels within the recommended levels, with the other three being close (Rauthmann, 2013). Difficult items tend to be endorsed only by individuals that present higher levels in the latent trait, while easier items tend to be endorsed by more individuals. Finally, we assessed the information levels of each item isolated, estimating the amount of information that each of them provides for the measurement of the latent trait, which is an indicator of item quality (Vieira, Moreira Júnior, \& Potrich, 2019). In addition, we 
calculated the test information curve, which is a graphical representation of items' contribution to the total information of each factor (Castro et al., 2010).

\section{Measurement Invariance}

To test whether the SAPS can be meaningfully compared across gender and countries, we performed two multigroup confirmatory factor analysis (Davidov et al., 2014). Establishing measurement invariance is important, because otherwise one risks to "compare chopsticks with forks" (Chen, 2008). That is, we ensured that men and women understood the items on average equivalently. Results confirmed that the measure is invariant across participants gender, thus allowing its use for analysis which compare men and women differences regarding perfectionism. The comparisons between our data and original US data revealed a full metric invariance, which allows meaningful comparisons across correlations coefficients. However, the scalar invariance was only partially achieved. Nevertheless, as the number of items that were variant was small (below 50\%), meaningful comparisons are still possible across the measure (Vandenberg \& Lance, 2000).

The lack of studies assessing invariance of the SAPS (Walton, Hibbard, Coughlin, \& Coyl-Shepherd, 2018) prevent researchers to compare whether perfectionism is endorsed differently by different groups (e.g., across countries). Studies like Wang et al.'s (2007) suggest that there might be some cultural influence on the way people express perfectionism, since the authors found a different factor structure for a Chinese sample in comparison to the one that has been reported in other cultures (e.g., Japan, USA; Nakano, 2009; Slaney et al., 2001). Nevertheless, as invariance has not been substantially examined, it is hard to tell whether there are differences on the endorsement of perfectionism over different countries or whether this construct is understood in different ways by different groups. For instance, why is the factor 
structure of the SAPS different in China (Wang et al., 2007) and South Korea (Park, 2009), but relatively similar in Italy and the USA (Loscalzo et al., 2018)? We argue that more studies need to examine the invariance of the SAPS so that a better picture on why partial invariance has been found for some studies (Rice et al., 2018), but different structures have been reported for others. In the present study, we contribute to this debate by presenting evidence of full metric and partial scalar invariance between an individualistic and developed country (the US) and a collectivistic and developing country (Brazil).

\section{Convergent Validity}

Convergent validity was assessed by correlating both factors of the SAPS with personality traits and human values. In prior research (Ulu \& Tezer, 2010), neuroticism (emotional stability) was the main predictor of discrepancy, a finding which we replicated. Individuals who score high on the discrepancy factor are highly emotionally instable, are commonly preoccupied, possess low tolerance to frustration, and are insecure (Schultz \& Schultz, 2011; Stoeber \& Otto, 2006). Also, in line to the Ulu and Tezer (2010) findings, standards was positively correlated with openness to experience and conscientiousness. Those two traits represent characteristics seen in individuals that are related to competence (conscientiousness), and originality and imaginability (openness), for example. Our results are also in line with Rice et al. (2014) original findings about the correlations between the SAPS factors with personality traits. The authors found that discrepancy was positively associated with neuroticism, while standards was positively linked to conscientiousness.

Both factors of perfectionism were correlated with suprapersonal values. This value's subfunction represents the needs for aesthetics, cognition, and self-actualization (Gouveia et al., 2014). As perfectionists set high standards for themselves, it is natural 
that they endorse values that represent these types of needs, which would represent an improvement for themselves. Also, the standard factor was correlated with promotion, existence, and interactive values. Promotion values are characteristic for individuals who cherish self-enhancement and focus on personal goals (Gouveia et al., 2014), which can once again indicate someone who has high expectations for the self. The existence values express survival needs (Gouveia et al., 2014). Being thorough is an evolutionary advantage and increases survival chances which can explain the relations between existence values and perfectionism (with perfectionism being an extreme version of being thorough). Finally, interactive values are important to establish and maintain interpersonal relations (Gouveia et al., 2014). Perfectionists are individuals that desire social approval and recognition, looking for interpersonal approval to establish harmonious relationships, which helps to understand the results. Some of them present negative interpersonal tendencies (Flett, Hewitt, \& Sherry, 2016), while some are described as friendly and submissive (Slaney, Pincus, Uliaszek, \& Wang, 2006).

\section{Limitations}

We used a non-probabilistic convenience sample, which restricts the generalizability of the findings. In addition, when responding to questionnaires, scales or any other type of measure, individuals are influenced by factors external to the content to be evaluated, such as social desirability. This response bias is in fact a "masking" of the individual's actual psychological functioning. Thus, we suggest that future studies about perfectionism in Brazil include a measure of social desirability, test the temporal stability (test-retest) of the SAPS, and acquire a more diversified sample of the participants (e.g., regarding age and education). Also, while the Ten-Item Personality Inventory was developed to measure the Big 5 with high validity (e.g., 
content validity), it comes with its costs: lower reliability levels. Thus, future studies could benefit from using a more reliable version of the Big 5 .

One other limitation pertains to the average age difference of 5.5 years between the Brazilian and US-American sample. This might have added a confound when we tested for measurement invariance across both countries. However, the link between perfectionism and age is typically small (e.g., Stoeber \& Stoeber, 2009). We therefore do not assume that the age difference between both samples led to partial invariance. Instead, we attribute it to cross-cultural differences.

\section{Implications for Practice, Advocacy, Education/Training, and Research}

Our research has several implications of a better understanding of perfectionism. As stated above, research has shown significant relations of perfectionism with several variables that can affect our quality of life, such as anxiety and emotional exhaustion (Flaxman et al., 2012), perceived stress and drinking to cope (Rice \& Arsdale, 2010), hopelessness and life satisfaction (Gnilka et al., 2013), and well-being (Wang et al., 2007). Therefore, the expansion of research on perfectionism and its underlying characteristics allow a more accurate understanding on how it affects our lives. And these understandings are vital when dealing with clients with perfectionisms, helping counseling psychologists to develop goal regulations and diminishing the impact that it might have in their lives.

The SAPS can be useful to Brazilian psychologists in screening perfectionism traits, using it as a semi-structured interview. That is, it allows to follow-up with questions to each item. For example, if a client agreed with the item "Doing my best never seems to be enough", it is possible to ask follow-up questions related to the antecedences and consequences of this belief. This in turn helps to plan interventions to reduce the maladaptive aspects of perfectionism. Counselling clients score higher on the 
discrepancy factor of the SAPS and evaluate themselves more critically compared to nonclients (Rice \& Taber, 2019). This can lead to developing and maintaining psychological distress (Suh, Sohn, Kim, \& Lee, 2019). The authors suggested that appropriate interventions reduce the maladaptive effects of perfectionism, and consequently improve mental health. In the absence of a psychometrically sound measure of perfectionism in Brazil, researching the effectiveness of interventions would be compromised.

Importantly, providing a powerful measure to evaluate perfectionism in Brazil is an advance to better understand perfectionism in different cultures, such as the academic. Hamilton and Schweitzer (2000) found that higher levels of perfectionism are associated with an increased vulnerability to suicide ideation. In another research, perfectionism significantly predicted academic stress, imposter syndrome, and communication anxiety (Cowie, Nealis, Sherry, Hewitt, \& Flett, 2018). Thus, assessing perfectionism in a reliable way allows to identify students more easily (e.g., through voluntary screening test) and offer help if necessary.

Finally, in academic research, our results show that the SAPS can be used in future studies to evaluate perfectionism in Brazil. Such studies could evaluate whether discrepancy is related to depression and anxiety, in line with self-discrepancy theory (Higgins, 1987). Future studies could further investigate the role of perfectionism in an occupational or academic context. We expect that individuals high in discrepancy can delay the progress of their professional, social, and academic activities because they focus too strongly on specific aspects of their work. The same pattern could be found in academia, with maladaptive perfectionists presenting low satisfaction in class, as well as poor mental health. Also, the validation of the measure in Brazil expands the possibility of using the scale in cross-cultural studies. 


\section{References}

Agência IBGE (2019). PNAD Contínua: taxa de desocupação é de 12,4\% e taxa de subutilização é de 24,6\% no trimestre encerrado em fevereiro de 2019.

Retrieved from https://agenciadenoticias.ibge.gov.br/agencia-sala-deimprensa/2013-agencia-de-noticias/releases/24109-pnad-continua-taxa-dedesocupacao-e-de-12-4-e-taxa-de-subutilizacao-e-de-24-6-no-trimestreencerrado-em-fevereiro-de-2019 on 09/09/2019.

Arana, F. G., Furlan, L. (2016). Groups of perfectionists, test anxiety, and pre-exam coping in Argentine students. Personality and Individual Differences, 90, 169-173. https://doi.org/10.1016/j.paid.2015.11.001

Arana, F. G., Rice, K. G., \& Ashby, J. S. (2017). Perfectionism in Argentina and the United States: Measurement structure, invariance, and implications for depression. Journal of Personality Assessment, 1-12. https://doi.org/10.1080/00223891.2017.1296845

Ashby, J. S., Rice, K. G., \& Kutchins, C. B. (2008). Matches and mismatches: Partners, perfectionism, and premarital adjustment. Journal of Counseling Psychology, 55, 125-132. doi:10.1037/0022-0167.55.1.125

Baker, F. B. (2001). The Basics of Item Response Theory. Retrieved from http://eric.ed.gov/?id=ED458219

Cappelleri, J. C., Jason Lundy, J., \& Hays, R. D. (2014). Overview of classical test theory and item response theory for the quantitative assessment of items in developing patient-reported outcomes measures. Clinical Therapeutics, 36, 648662. doi:10.1016/j.clinthera.2014.04.006

Castro, S. M. D. J., Trentini, C. M., \& Riboldi, J. (2010). Teoria da resposta ao item aplicada ao Inventário de Depressão Beck. Revista Brasileira de Epidemiologia., 
13, 487-501. Retrieved from https://www.scielosp.org/scielo.php?pid=S1415790X2010000300012\&script=sci_arttext\&tlng=es

Chalmers, R. P. (2012). mirt: A Multidimensional Item Response Theory Package for the R Environment. Journal of Statistical Software, 48(6), 1-29.

Chen, F. F. (2007). Sensitivity of goodness of fit indexes to lack of measurement Invariance. Structural Equation Modeling: A Multidisciplinary Journal, 14, 464504. http://doi.org/10.1080/10705510701301834

Chen, F. F. (2008). What happens if we compare chopsticks with forks? The impact of making inappropriate comparisons in cross-cultural research. Journal of Personality and Social Psychology, 95, 1005-1018. https://doi.org/10.1037/a0013193

Cheung, G. W., \& Rensvold, R. B. (2002). Evaluating goodness-of-fit indexes for testing measurement invariance. Structural Equation Modeling: A Multidisciplinary Journal, 9, 233-255. http://doi.org/10.1207/S15328007SEM0902_5

Cowie, M. E., Nealis, L. J., Sherry, S. B., Hewitt, P. L., \& Flett, G. L. (2018). Perfectionism and academic difficulties in graduate students: Testing incremental prediction and gender moderation. Personality and Individual Differences, 123, 223-228. https://doi.org/10.1016/j.paid.2017.11.027

Curran, T., \& Hill, A. P. (2019). Perfectionism is increasing over time: A meta-analysis of birth cohort differences from 1989 to 2016. Psychological Bulletin, 145, 410429. https://doi.org/10.1037/bul0000138

Davidov, E., Meuleman, B., Cieciuch, J., Schmidt, P., \& Billiet, J. (2014). Measurement equivalence in cross-national research. Annual Review of Sociology, 40, 55-75. https://doi.org/10.1146/annurev-soc-071913-043137 
Elion, A. A., Wang, K. T., Slaney, R. B., \& French, B. H. (2012). Perfectionism in African American students: Relationship to racial identity, GPA, self-esteem, and depression. Cultural Diversity and Ethnic Minority Psychology, 18, 118-127. https://doi.org/10.1037/a0026491

Ferreira, M. C., Fischer, R., Porto, J. B., Pilati, R., \& Milfont, T. L. (2012). Unraveling the mystery of Brazilian Jeitinho: A cultural exploration of social norms. Personality and Social Psychology Bulletin, 38, 331-344. https://doi.org/10.1177/0146167211427148

Flaxman, P. E., Ménard, J., Bond, F. W., \& Kinman, G. (2012). Academics' experiences of a respite from work: effects of self-critical perfectionism and perseverative cognition on postrespite well-being. Journal of Applied Psychology, 97(4), 854865. doi:10.1037/a0028055

Flett, G. L., Hewitt, P. L., \& Sherry, S. B. (2016). Deep, dark, and dysfunctional: The destructiveness of interpersonal perfectionism. In V. Ziegler-Hill \& D. K. Marcus (Eds.), The dark side of personality (pp. 211-.229). Washington, DC: American Psychological Association.

Fortes, L. de S., Meireles, J. F. F., Neves, C. M., Almeida, S. S., Ferreira, M. E. C., Fortes, L. de S., ... Ferreira, M. E. C. (2015). Comportamento de risco para transtorno alimentar, insatisfação corporal, perfeccionismo e estado de humor em adolescentes do sexo feminino. Revista de Nutrição, 28, 371-383. https://doi.org/10.1590/1415-52732015000400004

Frost, R. O., Heimberg, R. G., Holt, C. S., Mattia, J. I., \& Neubauer, A. L. (1993). A comparison of two measures of perfectionism. Personality and Individual Differences, 14, 119-126. https://doi.org/10.1016/0191-8869(93)90181-2 
Frost, R. O., Marten, P., Lahart, C., \& Rosenblate, R. (1990). The dimensions of perfectionism. Cognitive Therapy and Research, 14, 449-468. https://doi.org/10.1007/BF01172967

Gaudreau, P. (2012). A methodological note on the interactive and main effects of dualistic personality dimensions: An example using the $2 \times 2$ model of perfectionism. Personality and Individual Differences, 52, 26-31. https://doi.org/10.1016/j.paid.2011.08.022

Gnilka, P. B., Ashby, J. S., \& Noble, C. M. (2013). Adaptive and maladaptive perfectionism as mediators of adult attachment styles and depression, hopelessness, and life satisfaction. Journal of Counseling \& Development, 91, 78-86. https://doi.org/10.1002/j.1556-6676.2013.00074.x

Gosling, S. D., Rentfrow, P. J., \& Swann, W. B. (2003). A very brief measure of the Big-Five personality domains. Journal of Research in Personality, 37, 504-528. https://doi.org/10.1016/S0092-6566(03)00046-1

Gouveia, V. V., Milfont, T. L., \& Guerra, V. M. (2014). Functional theory of human values: Testing its content and structure hypotheses. Personality and Individual Differences, 60, 41-47. https://doi.org/10.1016/j.paid.2013.12.012

Gouveia, V. V., Milfont, T. L., Fischer, R., \& Santos, W. S. (2008). Teoria funcionalista dos valores humanos. In M. L. M. Teixeira (Ed.), Valores humanos e gestão: Novas perspectivas (pp. 47-80). São Paulo: Editora Senac.

Hair, J. F. J., Black, W. C., Babin, B. J., \& Anderson, R. E. (2015). Multivariate Data Analysis (7 edition). Upper Saddle River, NJ: Prentice Hall.

Hamacheck, D. E. (1978). Psychodynamics of normal and neurotic perfectionsm. Psychology: A Journal of Human Behavior, 15, 27-33. 
Hamilton, T. K., \& Schweitzer, R. D. (2000). The cost of being perfect: Perfectionism and suicide ideation in university students. Australian and New Zealand Journal of Psychiatry, 34(5), 829-835. https://doi.org/10.1080/j.1440-1614.2000.00801.x

Hanel, P. H. P., \& Vione, K. C. (2016). Do student samples provide an accurate estimate of the general public? PLOS ONE, 11(12), e0168354. https://doi.org/10.1371/journal.pone.0168354

Hanel, P. H. P., \& Wolfradt, U. (2016). The "dark side" of personal values: Relations to clinical constructs and their implications. Personality and Individual Differences, 97, 140-145. https://doi.org/10.1016/j.paid.2016.03.045

Henrich, J., Heine, S. J., \& Norenzayan, A. (2010). The weirdest people in the world? Behavioral and Brain Sciences, 33(2-3), 61-83. https://doi.org/10.1017/S0140525X0999152X

Hewitt, P. L., \& Flett, G. L. (2004). Multidimensional Perfectionism Scale (MPS): Technical manual. Toronto, Canada: Multi-Health Systems.

Higgins, E. T. (1987). Self-discrepancy: A theory relating self and affect. Psychological Review, 94, 319-340. https://doi.org/10.1037/0033-295X.94.3.319

Hill, R. W., Huelsman, T. J., Furr, R. M., Kibler, J., Vicente, B. B., \& Kennedy, C. (2004). A new measure of perfectionism: the Perfectionism Inventory. Journal of Personality Assessment, 82, 80-91. https://doi.org/10.1207/s15327752jpa8201_13

Index Mundi (n.d.). GINI index (World Bank estimate) - Country Ranking. Retrieved from https://www.indexmundi.com/facts/indicators/SI.POV.GINI/rankings on $09 / 09 / 2019$.

Index of Economic Freedom (2019). Country rankings. Retrieved from https://www.heritage.org/index/ranking on 09/09/2019. 
Kajonius, P. J., Persson, B. N., \& Jonason, P. K. (2015). Hedonism, achievement, and power: Universal values that characterize the Dark Triad. Personality and Individual Differences, 77, 173-178. https://doi.org/10.1016/j.paid.2014.12.055

Kline, P. (2013). Handbook of Psychological Testing. Routledge.

Lee, J. C., Prado, H. S., Diniz, J. B., Borcato, S., da Silva, C. B., Hounie, A. G., ... do Rosário, M. C. (2009). Perfectionism and sensory phenomena: phenotypic components of obsessive-compulsive disorder. Comprehensive Psychiatry, 50, 431-436. https://doi.org/10.1016/j.comppsych.2008.11.007

Loscalzo, Y., Rice, S. P. M., Giannini, M., \& Rice, K. G. (2018). Perfectionism and Academic Performance in Italian College Students. Journal of Psychoeducational Assessment, 1-9. https://doi.org/10.1177/0734282918800748

Maia, B. R., Soares, M. J., Gomes, A., Marques, M., Pereira, A. T., Cabral, A., ... Macedo, A. (2009). Perfectionism in obsessive-compulsive and eating disorders. Brazilian Journal of Psychiatry, 31, 322-327. https://doi.org/10.1590/S151644462009005000004

Milfont, T. L., \& Fischer, R. (2010). Testing measurement invariance across groups: Applications in cross-cultural research. International Journal of Psychological Research, 3, 111-130. http://doi.org/10.21500/20112084.857

Miura, M. A., Pilati, R., Milfont, T. L., Ferreira, M. C., \& Fischer, R. (2019). Between simpatia and malandragem: Brazilian jeitinho as an individual difference variable. PLoS ONE, 14. https://doi.org/10.1371/journal.pone.0214929

Moroz, M., \& Dunkley, D. M. (2019). Self-critical perfectionism, experiential avoidance, and depressive and anxious symptoms over two years: A three-wave longitudinal study. Behaviour Research and Therapy, 112, 18-27. https://doi.org/10.1016/j.brat.2018.11.006 
Nakano, K. (2009). Perfectionism, self-efficacy, and depression: preliminary analysis of the japanese version of the almost perfect scale-revised. Psychological Reports, 104, 896-898. https://doi.org/10.2466/PR0.104.3.896-908

Nascimento Junior, J. R. A., Vissoci, J. R. N., Lavallee, D., Vieira, L. F. (2015).

Adaptation and validation of the Sport Multidimensional Perfectionism Scale-2

(SMPS-2) for the Brazilian sport context. Motriz: Revista de Educação Física,

21, 125-136. https://doi.org/10.1590/S1980-65742015000200003

Organização para a Cooperação e Desenvolvimento Económico (2015). Programme for international students assessment (PISA): results from Pisa 2015. Retrieved from http://www.oecd.org/pisa/PISA-2015-Brazil-PRT.pdf on 09/09/2019.

Park, H. (2009). Validation of the Almost Perfect Scale-Revised. The Korean Journal of Counseling and Psychotherapy, 21, 131-149.

Peters, G. J. (2016). Quantitative Analysis Made Accessible. Retrieved from https://cran.rproject.org/web/packages/userfriendlyscience/userfriendlyscience.p $\underline{\mathrm{df}}$

R Development Core Team. (2015). R: A language and environment for statistical computing. Retrieved from https://cran.r-project.org/doc/manuals/fullrefman.pdf

Raiche, G., Walls, T. A., Magis, D., Riopel, M., \& Blais, J.-G. (2013). Non-graphical solutions for Cattell's scree test. Methodology: European Journal of Research Methods for the Behavioral and Social Sciences, 9, 23-29. http://doi.org/10.1027/1614-2241/a000051

Rauthmann, J. F. (2013). Investigating the MACH-IV with item response theory and proposing the trimmed MACH*. Journal of Personality Assessment, 95(4), 388397. https://doi.org/10.1080/00223891.2012.742905 
Revelle, W. (2013). Psych: Procedures for Personality and Psychological Research.

Retrieved from https://personality-project.org/r/psych.manual.pdf

Rice, K. G., \& Arsdale, A. C. V. (2010). Perfectionism, perceived stress, drinking to cope, and alcohol-related problems among college students. Journal of Counseling Psychology, 57, 439-450. https://doi.org/10.1037/a0020221

Rice, K. G., \& Ashby, J. S. (2007). An efficient method for classifying perfectionists. Journal of Counseling Psychology, 54, 72-85. doi:10.1037/0022-0167.54.1.72

Rice, K. G., \& Taber, Z. B. (2019). Measurement invariance and latent profiles of perfectionism in clients and nonclients. Journal of Counseling Psychology, 66(2), 210-223. https://doi.org/10.1037/cou0000326

Rice, K. G., Richardson, C. M. E., \& Tueller, S. (2014). The short form of the revised almost perfect scale. Journal of Personality Assessment, 96, 368-379. http://doi.org/10.1080/00223891.2013.838172

Rogoza, R., Wyszyńska, P., Maćkiewicz, M., \& Cieciuch, J. (2016). Differentiation of the two narcissistic faces in their relations to personality traits and basic values. $\begin{array}{llll}\text { Personality } \quad \text { and } \quad \text { Individual } & \text { Differences, }\end{array}$ http://doi.org/10.1016/j.paid.2016.02.038

Samejima, F. (1968). Estimation of Latent Ability Using a Response Pattern of Graded Scores1. ETS Research Bulletin Series, 1968(1), i-169. https://doi.org/10.1002/j.2333-8504.1968.tb00153.x

Schultz, S. E., \& Schultz, D. P. (2011). Teorias da personalidade (9ª ed.). São Paulo: Cengage Learning.

Schwartz, S. H. (1992). Universals in the content and structure of values: Theoretical advances and empirical tests in 20 countries. Advances in Experimental Social Psychology, 25, 1-65. https://doi.org/10.1016/S0065-2601(08)60281-6 
Schwartz, S. H. (2005). Robustness and fruitfulness of a theory of universals in individual human values. In A. Tamayo \& J. B. Porto (Eds.), Values and behavior in organizations [in Portuguese] (pp. 21-55). Petrópolis, Brazil: Vozes.

Sherry, S. B., Gralnick, T. M., Hewitt, P. L., Sherry, D. L., \& Flett, G. L. (2014). Perfectionism and narcissism: testing unique relationships and gender differences. Personality and Individual Differences, 61-62, 52-56. http://doi.org/10.1016/j.paid.2014.01.007

Sherry, S. B., Mackinnon, S. P., Macneil, M. A., \& Fitzpatrick, S. (2012). Discrepancies confer vulnerability to depressive symptoms: A threewave longitudinal study. Journal of Counseling Psychology, 60, 112-126. http://doi.org/10.1037/a0030439

Slaney, R. B., Pincus, A. L., Uliaszek, A. A., \& Wang, K. T. (2006). Conceptions of perfectionism and interpersonal problems: evaluating groups using the structural summary method for circumplex data. Assessment, 13, 138-153. http://doi.org/10.1177/1073191105284878

Slaney, R. B., Rice, K. G., Mobley, M., Trippi, J., \& Ashby, J. S. (2001). The revised almost perfect scale. Measurement and evaluation in counseling and development, 34, 130-145.

Smith, M. M., Sherry, S. B., Chen, S., Saklofske, D. H., Mushquash, C., Flett, G. L., \& Hewitt, P. L. (2017). The perniciousness of perfectionism: A meta-analytic review of the perfectionism-suicide relationship. Journal of Personality. https://doi.org/10.1111/jopy.12333

Stevens, J. P. (2012). Applied Multivariate Statistics for the Social Sciences. London: Routledge. 
Stoeber, J., \& Otto, K. (2006). Positive conceptions of perfectionism: approaches, evidence, challenges. Personality and Social Psychology Review, 10, 295-319. https://doi.org/10.1207/s15327957pspr1004_2

Stoeber, J., \& Stoeber, F. S. (2009). Domains of perfectionism: Prevalence and relationships with perfectionism, gender, age, and satisfaction with life. Personality and Individual Differences, 46(4), 530-535. doi:10.1016/j.paid.2008.12.006

Suh, H., Sohn, H., Kim, T., \& Lee, D.-G. (2019). A review and meta-analysis of perfectionism interventions: Comparing face-to-face with online modalities. Journal of Counseling Psychology, 66(4), 473-486. https://doi.org/10.1037/cou0000355

Tabachnick, B. G., \& Fidell, L. S. (2013). Using multivariate statistics (6th ed.). New York: Allyn \& Bacon.

Transparency Internacional (2018). Corruption perceptions index 2018. Retrieved from https://www.transparency.org/files/content/pages/2018_CPI_Executive_Summar y.pdf on 09/09/2019.

Ulu, I. P., \& Tezer, E. (2010). Adaptive and maladaptive perfectionism, adult attachment, and big five personality traits. The Journal of Psychology, 144, 327340. https://doi.org/10.1080/00223981003784032

Vandenberg, R. J., \& Lance, C. E. (2000). A review and synthesis of the measurement invariance literature: Suggestions, practices, and recommendations for organizational research. Organizational Research Methods, 3, 4-70.

\section{https://doi.org/10.1177/109442810031002}

Vieira, K. M., Moreira Junior, F. D. J., \& Potrich, A. C. G. (2019). Financial education indicator: proposal of an instrument from the Item Response Theory. Educação \& Sociedade, 40, 1-33. https://doi.org/10.1590/es0101-73302018182568 
Walton, G. E., Hibbard, D. R., Coughlin, C., \& Coyl-Shepherd, D. D. (2018). Parenting, personality, and culture as predictors of perfectionism. Current Psychology, 113. https://doi.org/10.1007/s12144-018-9793-y

Wang, K. T., Permyakova, T. M., \& Sheveleva, M. S. (2016). Assessing perfectionism in Russia: Classifying perfectionists with the Short Almost Perfect Scale.

\section{Personality and Individual Differences, 92, 174-179.}

\section{https://doi.org/10.1016/j.paid.2015.12.044}

Wang, K. T., Slaney, R. B., \& Rice, K. G. (2007). Perfectionism in Chinese university students from Taiwan: A study of psychological well-being and achievement motivation. Personality and Individual Differences, 42, 1279-1290.

https://doi.org/10.1016/i.paid.2006.10.006

Appendix. Items in Brazilian-Portuguese and English.

01. Tenho grandes expectativas para mim mesmo(a). (I have high expectations for myself) 02. Fazer o meu melhor nunca parece ser o suficiente. (Doing my best never seems to be enough.)

03. Mantenho padrões altos quanto a mim mesmo(a). (I set very high standards for myself.)

04. Muitas vezes me sinto desapontado após concluir uma tarefa, porque sei que poderia ter feito melhor. (I often feel disappointment after completing a task because I know I could have done better.)

05. Tenho uma forte necessidade de buscar fazer o melhor. (I have a strong need to strive for excellence.)

06. Minha performance raramente atende aos meus padrões. (My performance rarely measures up to my standards.) 
07. Eu espero o melhor de mim mesmo(a). (I expect the best from myself.)

08. Quase nunca estou satisfeito com a minha performance. (I am hardly ever satisfied with my performance.) 


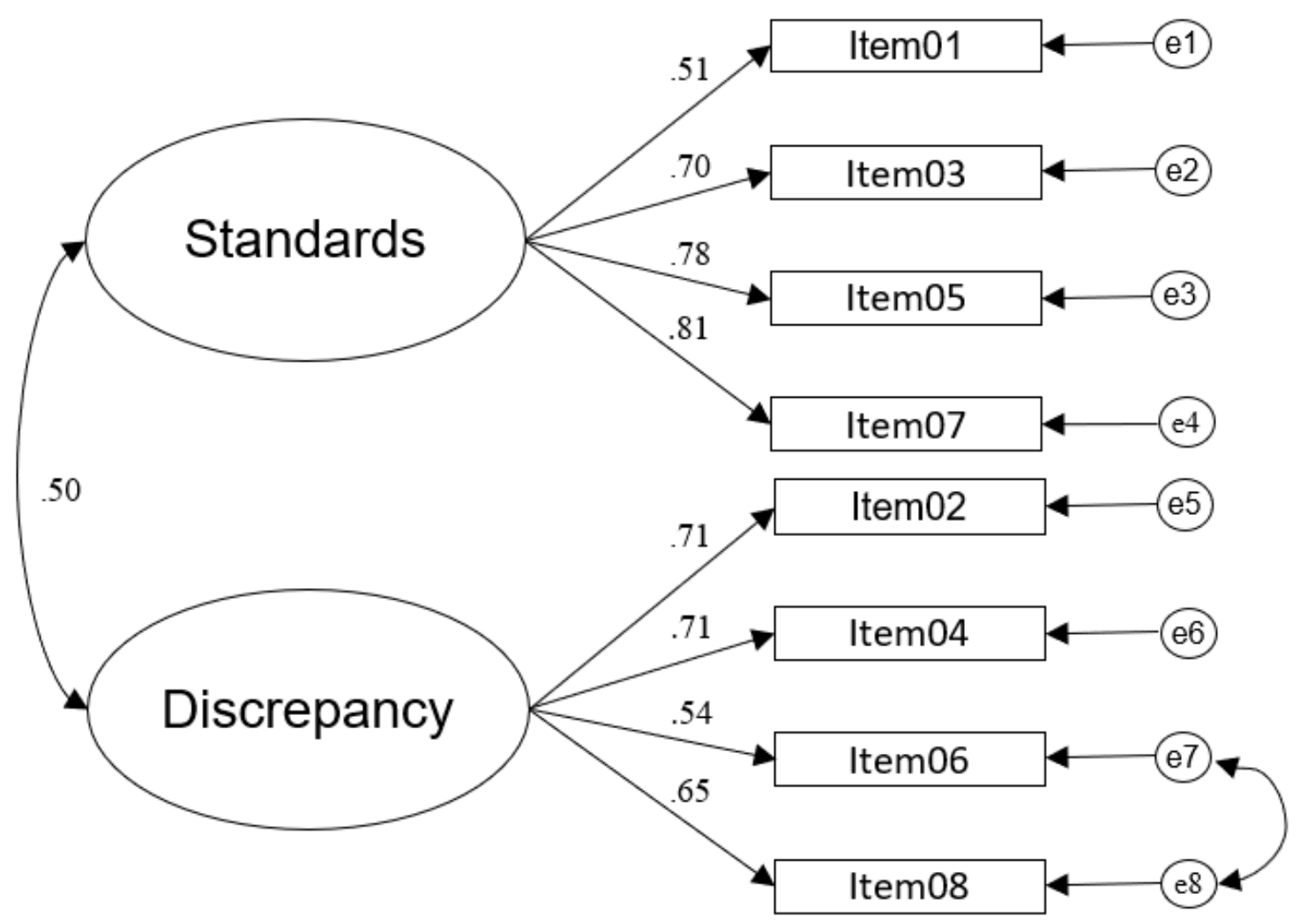

Figure 1. Factorial structure of SAPS in Brazil. 
Item information trace lines

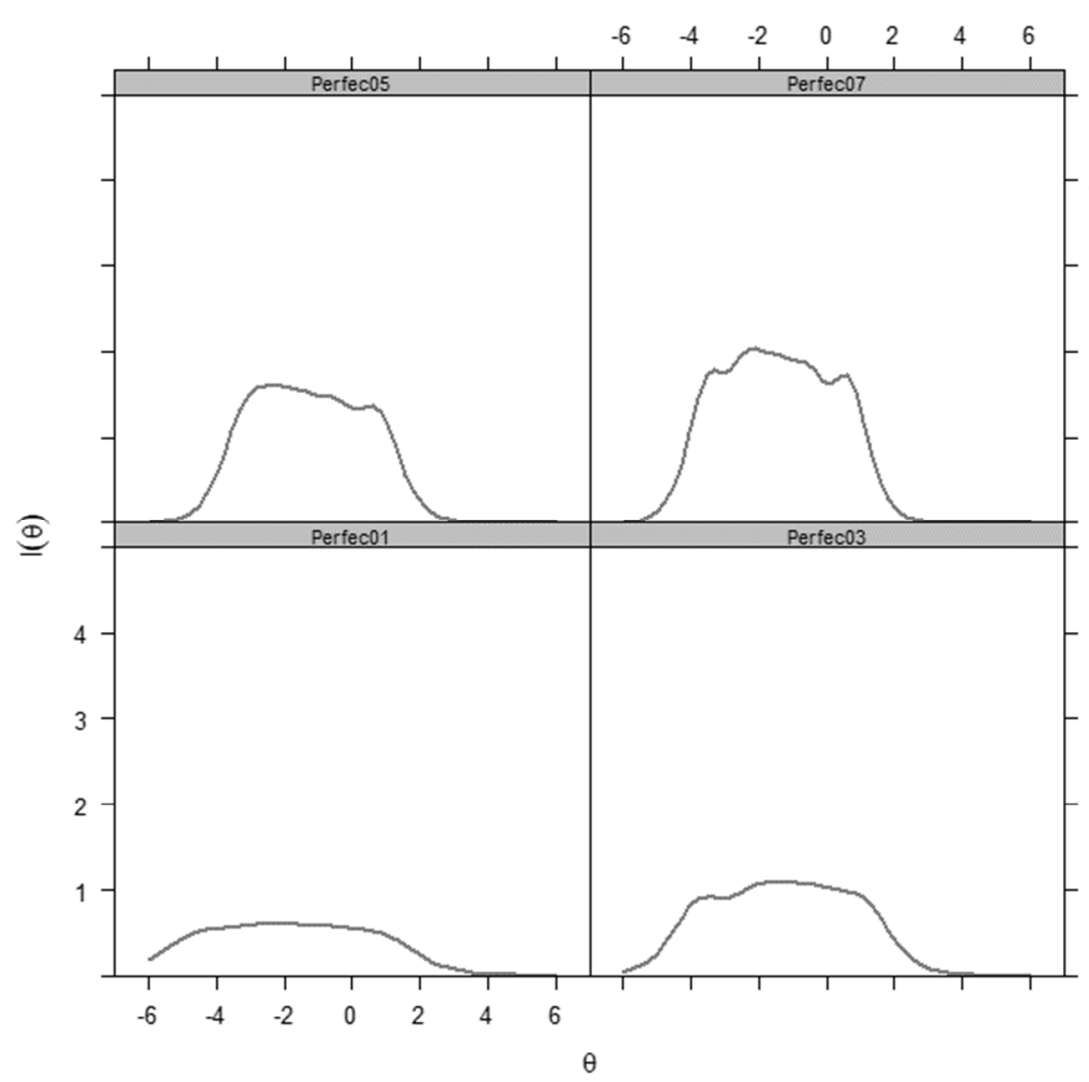

Item information trace lines

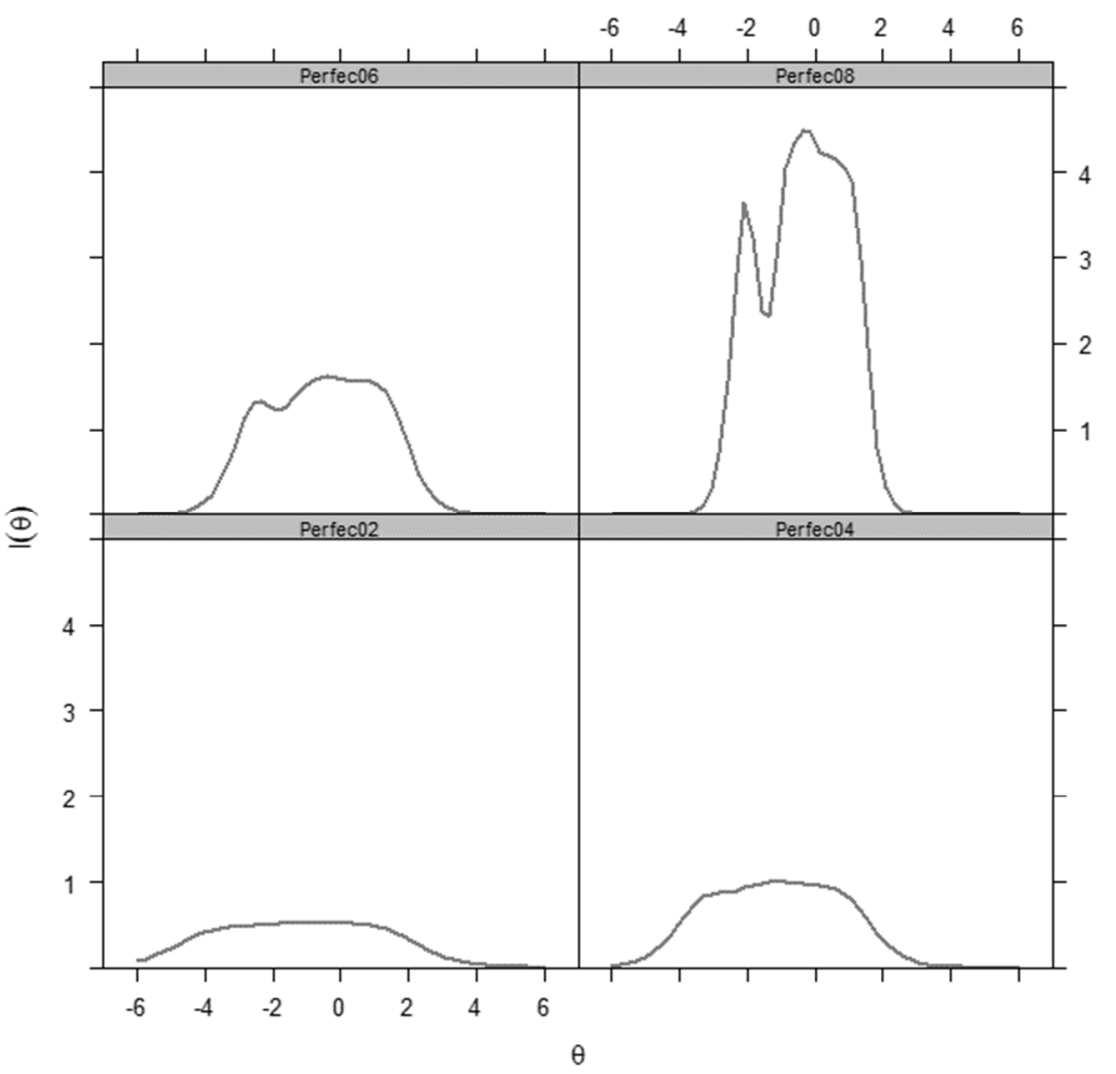

Figure 2. Item information curves of SAPS in Brazil (Left=Standards items). 


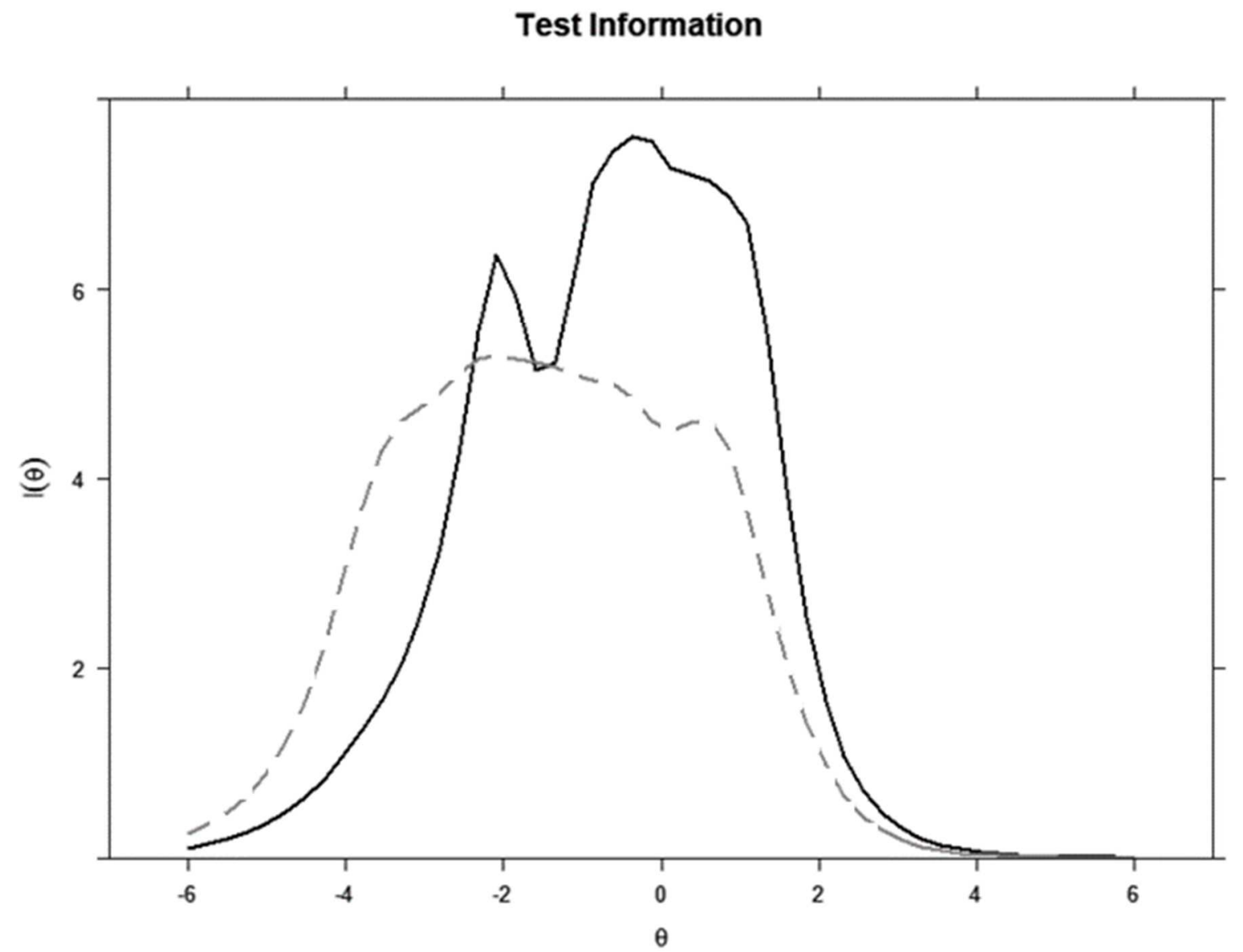

Figure 3. Test information curves for the SAPS in Brazil (Dashed=Standards items). 
Table 1

Factorial structure of the SAPS.

\begin{tabular}{cccc}
\hline \multirow{2}{*}{ Items } & \multicolumn{3}{c}{ Loadings } \\
\cline { 2 - 4 } Item08 & $.92^{*}$ & -.16 & .79 \\
Item06 & $.80^{*}$ & -.14 & .59 \\
Item04 & $.64^{*}$ & .04 & .42 \\
Item02 & $.50^{*}$ & .18 & .33 \\
Item01 & -.22 & $.66^{*}$ & .39 \\
Item07 & -.07 & $.65^{*}$ & .40 \\
Item05 & .15 & $.63^{*}$ & .47 \\
Item03 & .25 & $.57^{*}$ & .48 \\
\hline Number of items & 4 & 4 & \\
Eigenvalues (Rotated) & 2.25 & 1.62 & \\
Explained Variance (Rotated) & $28 \%$ & $20 \%$ &
\end{tabular}

Note: $\mathrm{h}^{2}=$ communalities; ${ }^{*}=$ loadings higher than .364 
Table 2

Item parameters of the SAPS in Brazil

\begin{tabular}{lcccccccc}
\hline Item & $a$ & $b_{1}$ & $b_{2}$ & $b_{3}$ & $b_{4}$ & $b 5$ & $b 6$ & $\begin{array}{c}b 1-b 6 \\
\text { (means) }\end{array}$ \\
\hline $\begin{array}{c}\text { Discrepancy } \\
\text { Item02 }\end{array}$ & 1.279 & -3.763 & -2.212 & -1.270 & -0.721 & 0.209 & 1.232 & -1.09 \\
Item04 & 1.769 & -3.230 & -1.938 & -1.372 & -0.904 & -0.139 & 0.852 & -1.12 \\
Item06 & 2.260 & -2.509 & -1.126 & -0.512 & -0.065 & 0.682 & 1.372 & -0.36 \\
Item08 & 3.814 & -2.056 & -0.853 & -0.381 & -0.071 & 0.496 & 1.103 & -0.29 \\
$\quad$ Standards & & & & & & & & \\
Item01 & 1.375 & -4.501 & -3.083 & -2.521 & -1.755 & -0.703 & 0.743 & -1.97 \\
Item03 & 1.859 & -3.715 & -2.269 & -1.608 & -0.925 & -0.113 & 1.034 & -1.27 \\
Item05 & 2.261 & -3.147 & -2.677 & -2.085 & -1.396 & -0.487 & 0.731 & -1.51 \\
Item07 & 2.576 & -3.500 & -2.467 & -2.108 & -1.382 & -0.543 & 0.632 & -1.56 \\
\hline \multicolumn{2}{l}{ Note. a=discrimination; $\mathrm{b}_{1}-\mathrm{b}_{6}=$ threshold. } & & & & &
\end{tabular}


Table 3

Measurement equivalence of the SAPS across gender and country.

\begin{tabular}{lcccc}
\hline \multicolumn{1}{c}{ Models } & CFI & RMSEA & $\Delta$ CFI & $\Delta$ RMSEA \\
\hline \multicolumn{1}{c}{ Gender } & & & & \\
Configural invariance & .909 & .099 & - & - \\
Metric invariance & .913 & .090 & .004 & .009 \\
Scalar invariance & .913 & .084 & .000 & .006 \\
\multicolumn{1}{c}{ Country } & .932 & .091 & - & - \\
Configural invariance & .929 & .086 & .003 & .005 \\
Metric invariance & .913 & .089 & .016 & .003 \\
Scalar invariance & .921 & .087 & .008 & .001 \\
Partial Scalar & & & & \\
\hline
\end{tabular}

Note. $\Delta=$ differences between the current and the previous model; $\mathrm{a}=$ the intercept of items 1 and 5 were released to achieve scalar invariance. 
Table 4

Correlations between perfectionism, and personality traits and human values.

\begin{tabular}{l|cc}
\hline \multicolumn{1}{c}{ Personality traits } & Discrepancy & Standards \\
Openness to experiences & -.045 & $.311 * *$ \\
Conscientiousness & $-.127 *$ & $.313 * *$ \\
Extraversion & $-.162^{* *}$ & .048 \\
Agreeableness & $-.124 *$ & -.032 \\
Emotional Stability & $-.311^{* *}$ & .058 \\
$\quad$ Human values & & \\
Excitement & .029 & .037 \\
Suprapersonal & $.244 * *$ & $.317 * *$ \\
Interactive & -.004 & $.139 *$ \\
Promotion & .055 & $.283 * *$ \\
Existence & .085 & $.237 * *$ \\
Normative & -.078 & .092 \\
\hline
\end{tabular}

Note: $* p<.05, * * p<.01$ 
S. Table 1

Factorial structure of the SAPS, using Maximum Likelihood.

\begin{tabular}{cccc}
\hline \multirow{2}{*}{ Items } & \multicolumn{3}{c}{ Loadings } \\
\cline { 2 - 4 } Item08 & $.91^{*}$ & -.12 & .79 \\
Item06 & $.78^{*}$ & -.10 & .59 \\
Item04 & $.64^{*}$ & .07 & .42 \\
Item02 & $.50^{*}$ & .20 & .33 \\
Item01 & -.22 & $.65^{*}$ & .39 \\
Item07 & -.05 & $.63 *$ & .40 \\
Item05 & .13 & $.64 *$ & .47 \\
Item03 & .24 & $.59 *$ & .48 \\
\hline Number of items & 4 & 4 & \\
Eigenvalues (Rotated) & 2.33 & 1.80 & \\
Explained Variance (Rotated) & $30 \%$ & $18 \%$ & \\
\hline
\end{tabular}

Note: $\mathrm{h}^{2}=$ communalities; ${ }^{*}=$ loadings higher than .364 